\title{
Business Model of Green Finance under the Background of "Internet Plus": A Case Study of Ant Forest
}

\author{
Xuan Zheng, Qingjun Meng \\ School of Business, Hohai University, Nanjing, China \\ Email:xuan_zoe@126.com
}

How to cite this paper: Zheng, $X$. and Meng, Q.J. (2018) Business Model of Green Finance under the Background of "Internet Plus": A Case Study of Ant Forest. Open Journal of Social Sciences, 6, 127-134. https://doi.org/10.4236/jss.2018.68010

Received: July 27, 2018

Accepted: August 20, 2018

Published: August 23, 2018

Copyright ( $) 2018$ by authors and Scientific Research Publishing Inc. This work is licensed under the Creative Commons Attribution International License (CC BY 4.0).

http://creativecommons.org/licenses/by/4.0/

Open Access

\begin{abstract}
With the coming of the new era, Internet finance and green finance have a new trend of integration, which promotes the innovation of business mode. The ant forest is taken as an example to dig and decompose its unique business model. On the basis of the diamond model of business model, advantages of the commercial model of Ant Forest are analyzed from three aspects: business object, business process and business performance, and five modules: resource integration, product, stakeholder, profit and risk. Research also finds out the shortage of the commercial model of Ant Forest, and put forward some suggestions for its further development. In order to obtain long-term development, the Ant Forest needs to develop more diversified functions, speed up the process of carbon trading and attract more folk capital.
\end{abstract}

\section{Keywords}

Internet Finance, Green Finance, Business Mode, Ant Forest, Diamond Model

\section{Introduction}

Under the new normal of China's green economy development, Internet finance and green finance have mutual promotion relationship [1]. Internet finance refers to the new financial business model that the traditional financial institutions and Internet enterprises use information technology to achieve financial intermediation, payment, investment and information intermediary services. Green finance means that the financial institutions consider the environmental protection factors in the investment and financing decisions, guiding the capital flow 
to the green industry, and promoting the sustainable development of the society through the guidance of the social and economic resources.

Ant Forest, as one of the main products of the "Internet plus green finance", has fully demonstrated the innovation of the business model of "Internet plus green finance". In August 27, 2016, The Ant Financial company opened up "Ant Forest" for consumers on Alipay, which is the largest personal carbon account in the world so far. Figure 1 shows the interface of Ant Forest, which can be entered through the Alipay application. Users get energy through low-carbon behavior and can view their trees on the forest map after planting trees with accumulated energy.

Under the background of "Internet plus green finance", Ant Forest has its unique commercial model, as well as its possible advantages and limitations, which can provide a reference for the innovation of other business models under "Internet plus green finance". In regard to business models of the financial industry, Ren Xiaoxun and Qiao Hanwe propose a new approach named "diamond model approach" for analyzing a business model, which can make a comprehensive analysis of business models of financial companies from 3 levels: business object, business process and business performance, and 5 modules: product, stakeholder, resource integration ability, return and risk [2].

Figure 2 shows the diamond model of Ant Forest's business model from 3 levels and 5 modules. On the basis of the diamond model of business models, this paper will analyze the advantages of the business model of Ant Forest, and put forward the shortcomings and relevant suggestions.

\section{Advantages of the Business Model of Ant Forest}

\subsection{Resource Integration Ability}

In terms of capital structure, Ant Forest mainly relies on its own investment and the support from public funds. At the very beginning of the project, Ant Forest

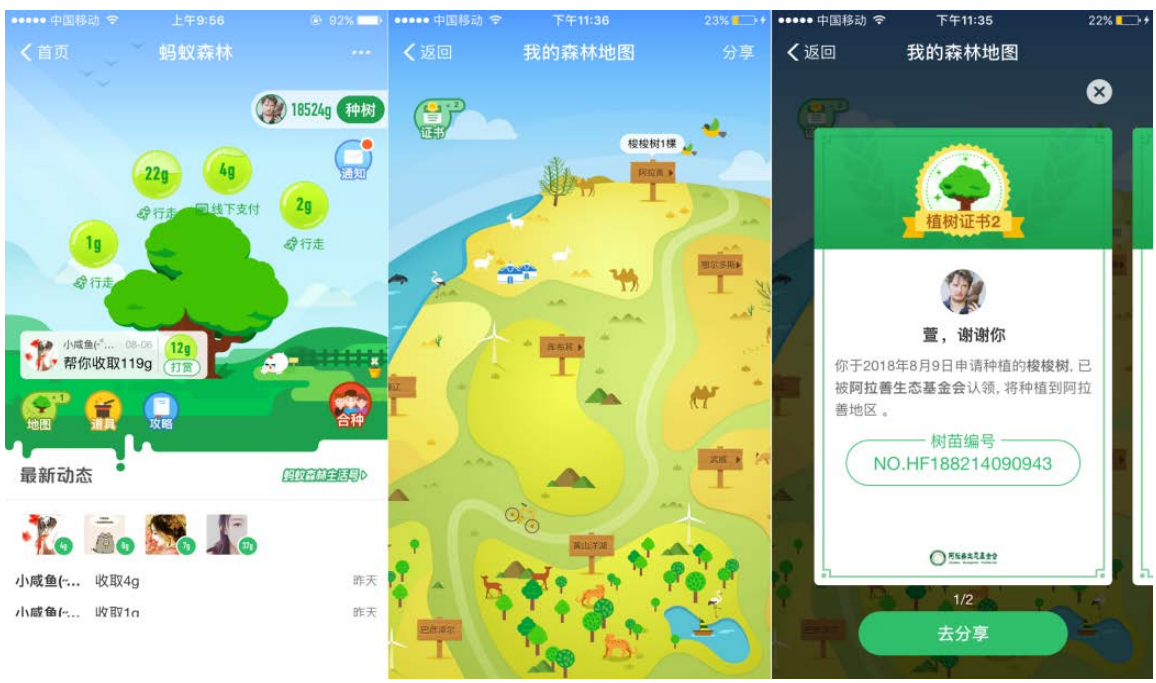

Figure 1. The interface of Ant Forest. 


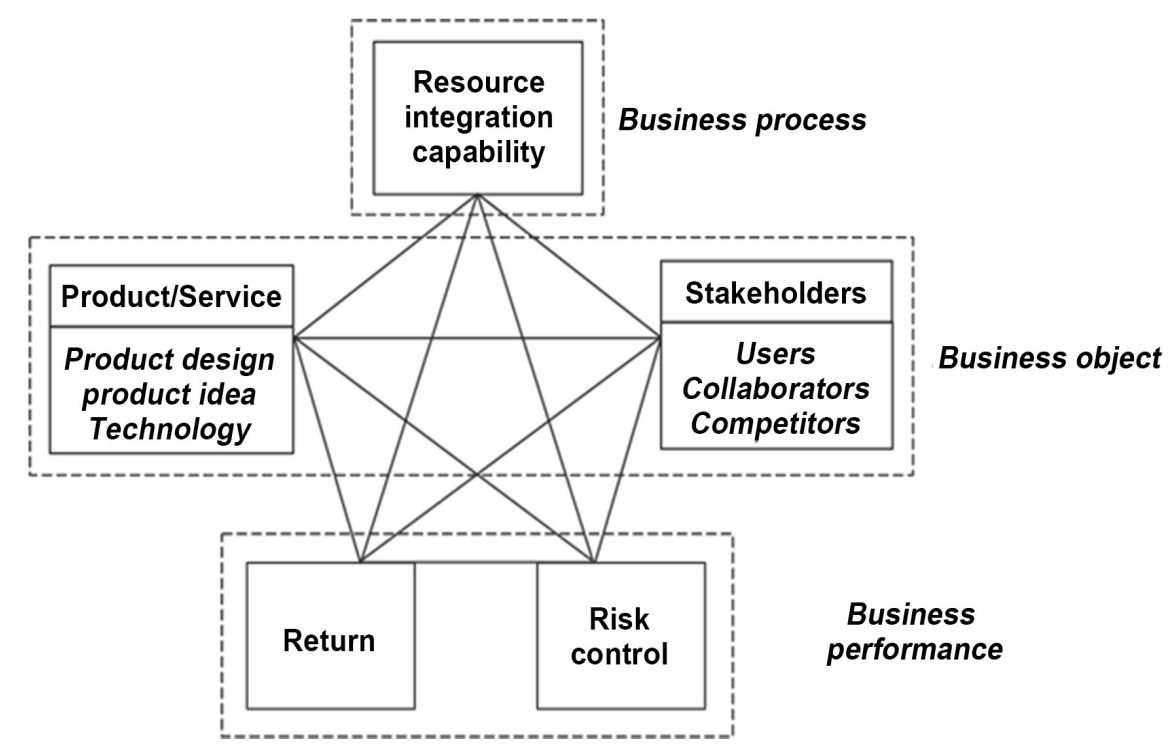

Figure 2. The diamond model of Ant Forest's business model [2].

was strongly supported by the Alibaba Public Welfare Foundation. Later, it succeeded in winning the olive branch of the major foundations because of its tremendous influence, including the Alxa SEE Foundation, the China Green Foundation, the China Green Carbon Foundation and the Elion Foundation. In terms of collaborator relationship, Ant Forest has attracted many stakeholders, such as foundations and technology companies. Ant Forest drives innovation with science and technology. The development of digital technology has helped Ant Forest complete the calculation method of individual emission reduction. In the future, Ant Forest plan to attract more participants. In terms of profit model, there will be unlimited imagination for the future commercial layout of carbon trading. In the early days of the Ant Forest, the "green energy" accumulated by the personal carbon account is purchased by public welfare foundations to convert it into tree planting behavior. The second step is to carry out the trade of emission reduction projects and encourage enterprises and individuals to buy. The third step is to establish a globally recognized individual "carbon account", which enables consumers to participate in the future trading and investment in the carbon market. This may achieve a "win-win" between social welfare promotion and pollution reduction [3]. The future development of Ant Forest will be limitless. When China's carbon trading market matures, Ant Forest will rely on its user stickiness to achieve large-scale profit.

\subsection{Product/Service}

The product design of Ant Forest combines many innovative ideas, including game-oriented product design, micro-commonweal, micro-social networking, carbon accounts and so on. First, the game-based product design caters to the psychological needs of the users, especially young consumers. Second, through the form of public welfare: "donating trees", user are given the opportunity to 
express personal value and social value, which is easy to enhance the stickiness of users. Third, the addition of the micro-social function can improve the user experience, meeting young people's needs of social interaction. Ant Forest activates Alipay's social pond through an open social circle, and thus greatly increases user activity [4]. Fourth, the new product concept of "carbon account" endues individual emission reduction with value meanings. This "carbon finance tool" has sowed the seeds of green finance to the public and portrayed a broad and imaginative prospect for the Inclusive Finance and the future business layout of Ant Forest. In addition, Ant Forest has introduced some new and high technology, such as "Electronic Scarecrow", UAV aerial survey technology, artificial intelligence and so on. The application of these "black technologies" enhances users' sense of reality, participation and trust.

\subsection{Stakeholder}

\subsubsection{Great Consumer Resources}

Attached to Alipay's huge user base, Ant Forest attains great consumer resources. Alipay's 2017 National Bill shows that 520 million users in China have used Alipay. Attached to the huge user base of the Alipay platform, Ant Forest is easy to attract large customer groups. By the end of 2017, the number of its users has reached 280 million, with a total reduction of 2.05 million tons. In addition, Ant Forest has attracted a large user group and formed a high user stickiness by the micro-social networking function, game-oriented design, and public-interest concept of universal environmental protection.

\subsubsection{Extensive Cooperators}

Ant Forest has extensive partners, including government, fund organizations, international organizations, public welfare organizations and high-tech companies. Besides Ant Finance, Alashan SEE, one of its public welfare partners, is also the initiator of Ant Forest. At the present stage, the public welfare projects of Ant Forest are supported by several fund organizations, which ensures a certain source of funds. The cooperation with high-tech companies has provided many technical supports for the projects of Ant Forest, such as the cooperation with XAircraft. The world's first digital Financial Alliance, launched in collaboration with the United Nations Environment Programme, has created more possibilities for Ant Forest to move towards the international arena.

\subsubsection{Smaller Competitors Threaten}

The Ant Financial Service Group, which is one of the first Internet financial service companies to arrange the Internet plus green financial business in China, has a strong competitiveness in this industry. Ant Forest is now the world's largest personal carbon account platform and the first practitioner of carbon accounts. Alipay, an important platform with the collection of various consumption scenes, has also given the Ant Forest a core competitiveness that is difficult to imitate and replace. 


\subsection{Income and Risk}

\subsubsection{Return}

In terms of return module, Ant Forest uses its innovative business model to achieve a win-win result between business interests and environmental goals. At present, Ant Forest mainly creates revenue for Alipay by encouraging consumption and attracting businesses to join the platform. The using frequency of Alipay APP's payments for both online and in-person transactions has greatly increased, improving earnings growth to a large extent. At this stage, the profit model of Ant Forest is still in its infancy. In the future, there is a great potential for the profitability of Ant Forest. Ant forest has won a good reputation from public welfare. In the future, the Ant Forest is building carbon account and setting up carbon trading, and the huge profitability of the carbon trading market may bring huge profits to the company.

\subsubsection{Risk}

In terms of risk control module, the trust risk of Ant Forest has been effectively controlled. When Ant Forest has just appeared, many users have great doubts about the authenticity of the public welfare projects, but the application of "Electronic Scarecrow" and other technologies makes the operation mode of Ant Forest more transparent, greatly reducing the risk of trust. For more than a year after the introduction of the Ant Forest, users' trust to it has gradually increased, and the voice of suspicion is gradually replaced by the voice of recognition and support. In general, the trust risk of Ant Forest is in the controllable range at this stage.

\section{Limitations of the Business Model of Ant Forest}

\subsection{Single Product Function}

The main function of Ant Forest is planting trees. The current improvement measures are still focused on tree planting experience. With the gradual fading of enthusiasm for tree planting, the shortages of Ant Forest in user experience gradually emerged. For example, some users hold the view that the new-online poplar and Pinus sylvestris need too much energy, which reduces the power of planting trees; or the actual Haloxylon tree has a big difference from his imagination. For example, a civilian account can get $1 \mathrm{~g}$ of energy per 60 steps, and a poplar needs 215,680 grams from planting to growing, equivalent to 12.9408 million steps.

This reflects that the current functions can not meet the needs of users well. Therefore, the requirement of Ant Forest to develop diversified functions is becoming more and more urgent.

\subsection{Limited Source of Funds}

The main source of funding for the business model of Ant Forest comes from Ant Financial Service Group and various greening foundations, which is very limited. These funds may not support the cost of "national tree-planting trend". 
At present, the project itself has no obvious profit. Therefore, if it only relies on the company and foundations to pay the bill, the high cost is a question worth pondering. The cost of turning online virtual trees into real trees, maintenance cost for trees in the later stage and daily manpower expenses, etc., need huge amounts of funds to support continuously.

\subsection{Immature Profit Model}

At present, the product orientation of ant forest is commonweal, and it is committed to expanding user base for future layout. It will take some time to realize its profit model. Admittedly, the Ant Forest has a strong user stickiness, which can attract user traffic and promote more users to trade on Alipay. However, the life cycle of any game product is short, if Ant Forest only stays in the stage of the game-based "Internet + public" mode, it will not be conducive to its sustainable development. At present, the development of China's carbon trading market is still in its infancy. So it is still a long way to go for Ant Forest to enter the market and make profits.

\section{Suggestions}

\subsection{Improving the Product Design Scheme}

First of all, Relying on Ant Financial Service Group platform, Ant Forest can develop more functions to satisfy users' needs. For example, Ant Forest can enrich the product experience by investing in some projects related to green finance, or adding some more personalized functions, such as a tool that can measure how many carbon emissions are reduced by users, marking up the consumers' performance of energy saving and emission reduction on the Ant Forest page. In addition, more abundant consumption scenarios should be added, such as riding bikes and green office, so that more environmental behaviors of users can generate green energy.

\subsection{Increase Users' Trust}

Firstly, Ant Forest should disclose specific algorithms for green energy values to ensure the fairness of energy generation and conversion. When it comes to the interests of Alipay, such as encouraging people to buy tickets through Alipay and increasing the stickiness of new users, it should not set up a large energy gap. If there is obvious guidance, users will have an unpleasant experience. Secondly, Ant Forest should allow users to participate in the process of seedling growth, so that users can clearly see the growth of seedlings through photos and videos at all stages. Meanwhile it should increase the popularity of science about planting trees in the desert to reduce user disappointment.

\subsection{Speed up the Layout of Carbon Trading}

The most promising part of the development of Ant Forest is carbon trading. Therefore, the present task of Ant Forest is to accelerate the layout of carbon 
trading, promoting good interaction between environmental public welfare and a real business model. In order to realize the layout of carbon finance transactions, the next focus of development is to further expand carbon accounts, for example, to establish carbon accounts for small and medium-sized enterprises. While expanding its advantages in carbon trading, the company should comply with development and vicissitude of state policy in green finance, and prevent other competitors from grabbing the market preemption.

\subsection{Expand the Sources of Funding}

The fund chain of Ant Forest may have problems if it only relies on Alipay's capital sources. Therefore, in addition to public welfare funds, Alipay can consider to introducing folk capital. To some extent, folk capital can alleviate the financial pressure and achieve the sustainable development. One feasible way is to encourage companies and individuals with social responsibility to buy carbon emissions, making enterprises and individuals participate in future trading and investment in carbon market. Meanwhile, this will promote the improvement of carbon trading market.

\section{Summary}

Green finance provides the new possibility of the development for the current Internet finance and makes the resource allocation of Internet finance more reasonable. This paper takes Ant Forest as an example and explores its innovative business model of green finance under the background of "Internet plus". Ant forest is rooted in the all-round layout of Alibaba's Ant Financial, thus its business model has its inherent advantages. The advantages of Ant Forest's business model are analyzed from four aspects: resource integration ability, product/service, stakeholder, income and risk. However, at this stage, the combination of Internet finance and green finance is only in its initial stage, and it still has a long way to go. This paper puts forward some limitations of Ant forest: single product function, limited source of funds and immature profit model. On this basis, the paper puts forward relevant suggestions: the Ant Forest can improve its product design scheme, speed up the layout of carbon trading, and expand the sources of funding.

\section{Conflicts of Interest}

The authors declare no conflicts of interest regarding the publication of this paper.

\section{References}

[1] Liu, L., Zha, N. and Huang, X.D. (2017) The Organic Combination of Internet Finance and Green Finance: An Example of the New Energy Internet Financial Platform. Market Modernization, 7, 148-149.

[2] Ren, X.X., Qiao, H., Huang, Z.Y., He, L.P. and Wang, S.Y. (2015) Diamond Model 
of Business Models: A Case Study of Ping an Financial Mall. Management Review, 11, 231-240.

[3] Fan, J., Zhao, D.T. and Guo, T. (2012) Research on Carbon Emission Trading Mechanism from Consumer Perspective. China Soft Science, 6, 24-32.

[4] Hu, Y. and Zhang, X.M. (2018) The Game-Based Innovation Strategy of Environmental Communication in the Internet Age: Taking "Ant Forest” as An Example. Journalism Lover, 2, 74-77. 